\title{
MOTIVACIÓN A LA LECTURA EN NIÑOS DE EDADES
} TEMPRANAS

\section{MOTIVATION TO READ IN CHILDREN OF EARLY AGES}

\author{
Asdrúbal Emilfo Ayala Mendoza 1 \\ Jenny Maribel Arcos Tasigchana²
}

Recibido: 2021-06-05 / Revisado: 2021-07-16 / Aceptado: 2021-08-12 / Publicado: 2021-09-15

Forma sugerida de citar: Ayala-Mendoza, A. E. y Arcos-Tasigchana, J. M. (2021). Motivación a la lectura en niños de edades tempranas. Retos de la Ciencia. 5(e). 42-51. https://doi.org/10.53877/rc.5.e.20210915.04

\section{Resumen}

La acción de leer es una habilidad compleja con el fin de comprender el texto escrito. Los niños tienden a presentar problemas al momento de leer, generando dificultades en la comprensión lectora y afectando su rendimiento educativo, la responsabilidad de estimular a los niños a la lectura es de los padres, la escuela y la sociedad. Como objetivo de esta investigación es identificar aquellas prácticas motivadoras hacia la lectura en edades tempranas, expuestas por diferentes referentes teóricos, extraídos de fuentes primarias actualizadas, en las que se evidencian resultados positivos para el hábito lector de los niños. Esta investigación se realizó con un enfoque cualitativo, de nivel descriptivo, con el tipo bibliográfico documental, con un análisis de referencias. Los resultados muestran que las prácticas motivadoras de la lectura en edades tempranas son las aplicadas por los docentes, asi también existe imitación de los niños con padres que tienen hábitos lectores. La lectura dialógica que genera el papel de narrador en el niño y el uso del material bibliográfico como promotor de la relación entre el niño y el texto. La lectura es de vital importancia para la promoción de la calidad académica del estudiante, los métodos mágicos para estimular la lectura no existen y motivar adecuadamente al niño tendrá un resultado positivo en su desarrollo intelectual y académico. El docente como motivador es el apoyo para que el niño asuma el proceso lector; la familia es la encargada de estimular la actividad lectora en la primera infancia; la lectura de cuentos involucra a los niños como lectores y escritores activos; el uso de material de biblioteca genera una relación entre el niño y el texto; y la lectura dialógica crea un ambiente de motivación lectora igualitaria.

Palabras clave: Motivación, lectura, niños, edades tempranas, familia, libros.

\section{ABSTRACT}

The action of reading is a complex skill in order to understand the written text. Children tend to present problems when reading, generating difficulties in reading comprehension and affecting their educational performance, the responsibility of

\footnotetext{
${ }^{1}$ Magister en Psicopedagogía Talentos y Creatividad. Docente Investigador de la Universidad Tecnológica Indoamérica. Ecuador. E-mail: aayala2@indoamerica.edu.ec / ORCID: https://orcid.org/0000-0003-2444-176X 2 Estudiante de la Universidad Tecnológica Indoamérica. Ecuador. E-mail: jarcos5@indoamerica.edu.ec / ORCID: https://orcid.org/0000-0003-1654-2245
} 
stimulating children to read lies with parents, school and society. The objective of this research is to identify those motivational practices towards reading at early ages, exposed by different theoretical references, extracted from updated primary sources, in which positive results are evidenced for the reading habit of children. This research was carried out with a qualitative approach, at a descriptive level, with the documentary bibliographic type, with an analysis of references. The results show that the motivating practices for reading at early ages are those applied by teachers, as well as the imitation of children with parents who have reading habits. Dialogic reading that generates the role of narrator in the child and the use of bibliographic material as a promoter of the relationship between the child and the text. Reading is of vital importance for the promotion of the student's academic quality, magic methods to stimulate reading do not exist and motivating the child properly will have a positive result in his or her intellectual and academic development. The teacher as motivator is the support for the child to assume the reading process; the family is in charge of stimulating reading activity in early childhood; story reading involves children as active readers and writers; the use of library material generates a relationship between the child and the text; and dialogic reading creates an environment of equal reading motivation.

Keywords: motivation, reading, children, early ages, family, reading, books.

\section{INTRODUCCIÓN}

La acción de leer puede definirse como una habilidad compleja cuyo fin es comprender el texto escrito. Para Fonseca et al. (2019) es una "actividad intencional y voluntaria en la cual los lectores se comportan de acuerdo con las características del contenido, al objetivo de la lectura, a la temática o al tipo de tarea" (p. 92). El proceso lector demanda de la aplicación de destrezas básicas para el reconocimiento de las letras y palabras escritas; pero también, requiere de habilidades complejas que permitan realizar el procesamiento y comprensión de las ideas e información del libro; convirtiendo a la comprensión lectora en el pilar fundamental de la lectura.

Cada vez, es más frecuente los problemas en los niños al momento de leer, lo que conlleva a su vez a tener dificultades para la comprensión lectora y esto termina convirtiéndose en una deficiencia que tristemente acompañará al sujeto a lo largo de su vida afectando el ámbito estudiantil, profesional y personal. Argüelles (citado por Domingo, 2017) menciona: "la lectura es tan fastidiosamente importante que da vergüenza, miedo o rencor decir que no se lee, y que a pesar de eso se es feliz, inteligente, sensible, digno, justo" (p. 75). En este caso, el autor expone abrumadoramente la importancia de la lectura, y lo imprescindible que resulta convertirla en un hábito que se debe cultivar desde tempranas edades.

Es así que, la presente temática de estudio ha sido escogida, porque es un problema que afecta directamente el rendimiento educativo de los niños, discriminando lo que puede captar un estudiante dentro o fuera del aula de clase; siendo justamente este el motivo donde radica su importancia, al pretender exponer los aspectos que motivan leer a tempranas edades, proporcionando un análisis a profundidad de diversos autores, a fin de proveer un beneficio para la comunidad académica y sociedad en general. Desde luego, el uso de las nuevas tecnologías si bien permiten un acercamiento a un mundo instantáneo de información, casi visual en su totalidad, ha alejado a esta misma población de algo tan básico como es la lectura; formando un conglomerado sin motivación alguna para leer. 
Para Bernal (2017), los padres, docentes y la sociedad en general deberían enfocarse en la formación de niños y adolescentes para encarar el futuro y sus obstáculos, se da por hecho de manera errónea, puesto que los nativos digitales dominan y comprenden lo que leen; porque tienen facilidad para el manejo de las nuevas tecnologías, dejando de lado la lectura, ya sea por aburrimiento o simplemente porque no les llama la atención, lo que trae como consecuencia deficiencias lectoras.

Sin embargo, la problemática se torna aún más preocupante, porque existen docentes que carecen de hábitos lectores, por este motivo es casi imposible inculcar lo que no se practica, incurriendo en el mismo ciclo de falta de prácticas lectoras; que debe ser estudiado, corregido y consolidado en toda la sociedad. Roja y Cruzata (2016) considera que el fenómeno aqueja a la mayoría de los países en vías de desarrollo; y sobre todo a la población del área rural.

De acuerdo con Cortés y García (2017), el estímulo no solo proviene de la técnica del maestro o de su estrategia pedagógica; también se requiere de la intervención de factores como la ubicación del estudiante en el aula, el área física, los recursos y materiales didácticos e incluso menciona la postura del docente, al momento de iniciar una lectura; creando un ambiente agradable para motivar a los niños a leer; pero buscando estimular ese deseo de continuar haciéndolo. Cabe indicar, que para que un infante se sienta motivado a la lectura, el material que va a usar el profesor debe despertar su curiosidad y ser contextualizado, es decir, presentar situaciones familiares para el niño, que no resulten ajenas a su entorno; y que, a su vez, capten su atención.

Para Serna et al. (2017) el estímulo para el desarrollo del hábito lector proviene de imitar a adultos que estén cercanos a su entorno y que los niños consideren importantes. Según lo expuesto, se mantiene la esencia de comportamiento por imitación, donde los infantes van a emular la conducta integral de los progenitores, esto por ende incluye la práctica de la lectura. Se puede decir entonces, que el buen lector no nace, se hace; ya que resulta imposible la idea de un hogar con niños que gusten de la lectura con padres que tengan otras afinidades, las conductas se transmiten de acuerdo con las costumbres del entorno familiar. En este caso, el maestro debe convertirse en el nexo que el infante no posee en casa, para el acercamiento a la costumbre lectora.

La responsabilidad de estimular a los niños a la lectura debe ser por parte de sus padres, la escuela y la sociedad, debería darse de forma natural. Este fenómeno cultural se produce en muchas sociedades como la francesa o rusa, donde el gobierno impulsa proyectos tan masivos, que toda la población ve a la lectura como una actividad propia del ser humano y no como un simple proceso que se realiza para aprobar una determinada asignatura. Es así como, la delgada línea entre amar y rechazar la lectura, señalando al centro de educación como responsable directo de este suceso, puede incidir en la vida de todos aquellos infantes que pasan por sus aulas. (Bernal, 2017)

Un aprendizaje integral, con un ambiente agradable y con libre pensamiento van a influir de modo positivo en la motivación lectora. La sociedad por otro lado posee también gran influencia en este aspecto, lo que se ve en televisión, redes sociales y la radio trascienden en la mente del niño, partiendo desde un mensaje publicitario cotidiano hasta la comprensión textual de alguna obra emblemática de literatura, son un conjunto estimulante para la imaginación de un novel lector.

De lo antes expuesto, se puede establecer la siguiente pregunta de investigación: ¿cómo motivar a los niños a la lectura de forma eficaz en edades tempranas? De esta 
manera, el presente estudio tiene como propósito identificar aquellas prácticas motivadoras hacia la lectura en edades tempranas, expuestas por diferentes referentes teóricos, extraídos de fuentes primarias actualizadas, en las que se evidencian resultados positivos para el hábito lector de los niños.

\section{METODOLOGÍA}

Para determinar los factores que influyen en la motivación a la lectura en niños en edades tempranas, esta investigación se realizó con un enfoque cualitativo, de nivel descriptivo, con el tipo bibliográfico documental. La unidad de análisis se conformo por 25 fuentes primarias El criterio de inclusión determinado analizó cada una de las referencias de la unidad de análisis, identificando los documentos que se encuentren de acuerdo con el tema, exponiendo claramente la edad de los niños, la muestra con la que se trabajó, el país donde se realizó el estudio, el objetivo y los factores motivadores para la lectura.

En cambio, el criterio de exclusión suprime los escritos que no cumplen con todos los requisitos concretados para ser incluidos en el estudio; estableciendo una muestra de 19 bibliografías, a partir de las cuales se extraerán los resultados. Así mismo, para el desarrollo del levantamiento de datos, se utilizó como técnica el análisis documental, que es el proceso mediante el cual se estudian los documentos para obtener un subproducto derivado de las publicaciones originales.

El procesamiento y análisis de la información se realizó con el software Atlas Ti, lo cual, permitió construir datos necesarios para descripción de características representativas de cada publicación para la formación de los resultados. Finalmente, el documento aporta conclusiones cuyo propósito es complementar el conocimiento de la comunidad académica, científica y social, en relación con la motivación lectora en niños en edad temprana.

\section{RESULTADOS}

A partir de la revisión bibliográfica realizada se han identificado ocho referentes cuyos aportes son significativos para el tema en estudio, por lo que las ideas principales de los autores se describen a continuación:

López (2018), en su estudio, indica que los niños de preescolar, establecen una interacción entre la imagen y el texto, en este punto, el niño lleva a cabo el acto de leer partiendo de la figura, generando ideas a partir de deducciones con las que puede elaborar explicaciones de acuerdo con lo que ve escrito, por esta razón; Rojas y Cruzata (2016) mencionan que la comprensión lectora "es un conjunto de procesos psicológicos que procesan la información lingüística desde su recepción hasta que se toma una decisión" (p.340).

Para Godoy (2016) las prácticas de lectura en el nivel inicial deben construir espacios en los que el estudiante conviva con la comunidad de lectores y que a la vez logre recurrir de manera frecuente a los textos para que pueda informarse; además, se debe fomentar las experiencias literarias a través de los cuentos, las poesías, como parte de la literatura diaria, con el propósito de desarrollar el gusto lector. También es fundamental, hacerlos partícipes del funcionamiento de la biblioteca del salón, haciéndolos sentir como miembros de la red de lectura escolar. De esta forma podrán leer por medio de su maestro.

La estimulación temprana para el perfeccionamiento de la práctica lectora en niños de edad de preescolar implica la práctica de actividades en las que el niño promueve 
su propio aprendizaje, descubre personajes, imita sonidos, describe imágenes, imagina y elabora el desenlace de la lectura.

Según Cortés y García (2017) los niños con un entrenamiento de lenguaje activo en la educación inicial tendrán un perfeccionamiento oral más propicio para el proceso lecto - escritor. Otra práctica relacionada con la lectura interactiva en la edad de preescolar de acuerdo con Guevara y Rugerio (2017) son los cuentos y los juegos de roles dentro del salón, estas actividades mejoran notablemente las habilidades lectoras en los estudiantes, porque implica la comprensión de relatos, relación de eventos, identificación de palabras y sonidos; así como, la narración a partir del uso de imágenes, creando historias, rimas, experiencias personales, desarrollo de dibujos y los primeros trazos de escritura.

Así mismo, Acevedo (2016) considera que es muy significativo que "el estímulo lector comience de la mano de los padres desde las primeras edades, para que, de esta manera sobre el libro recaiga una gran carga afectiva y permita preparar el camino para el posterior desarrollo del hábito lector" (pág. 55). Según Mora y Morales (2016) así se forman a través de las actitudes constructivistas positivas de la familia una firme confianza en los niños para el uso de sus propias aptitudes que involucran el deseo de leer.

Para Medina y Leal (2019) es preciso impulsar las habilidades lectoras, por lo que se deben instituir técnicas que eviten la memorización mecánica, sin comprensión, por lo que se propone tres tipos de estrategias; "primero, establecer objetivos de lectura y actualizar conocimientos relevantes; segundo, crear inferencias de diferente tipo; y tercero, recapitular los contenidos, resumiendo para obtener conocimiento" ( $p$. 34). Con los aportes de los utores se presentan los siguientes resultados:

Tabla 1:

Criterios de Selección

\begin{tabular}{ccccc}
\hline Autor & País & Muestra & Edad & Objetivo \\
\hline & & & & Analizar las prácticas lectoras de los estudiantes \\
Mercado, & México & 45 & $5-7$ & a través de las descripciones que hicieron los
\end{tabular}

Ruth México estudiantes años maestros durante sus actividades de enseñanza en el transcurso de la investigación.

Cortés,

Alexandra;

García,

Giovanna

$$
\text { No }
$$

Colombia proporciona información
$0-6$

años Identificar las diferentes herramientas y estrategias pedagógicas para motivar la lectura que los docentes pueden implementar en el aula de clase; detallando en qué consiste cada una y qué trascendencia tiene para el niño en su desarrollo integral" (Cortés, Alexandra; García, Giovanna, 2017, p. 126)

Mejorar los hábitos lectores, intentando que

Lluch,

Gemma;

Sánchez, España 24

Sandra

Rojas,

Margarita;

Cruzata,

Perú

12

Alejandro lleguen a ser estables y que "los individuos integren la lectura en su estilo de vida. Para ello, 3-7 las acciones que la promocionan deben ser años consideradas como parte del proceso educativo y ciudadano y llevarse a cabo dentro y fuera del contexto escolar" (Lluch y Sánchez, 2017, pág. 3) Contribuir a la "solución de las dificultades identificadas mediante una estrategia didáctica con fundamentos pedagógicos y curriculares desde la perspectiva cognitiva, comunicativa e interactiva que permita dirigir el proceso de enseñanza y aprendizaje de la comprensión 
lectora de una manera creativa e innovadora" (Rojas y Cruzata, 2016, p. 338)

\begin{tabular}{|c|c|c|c|c|}
\hline $\begin{array}{l}\text { López, } \\
\text { Carmen }\end{array}$ & Colombia & 24 & $\begin{array}{l}5-6 \\
\text { años }\end{array}$ & $\begin{array}{l}\text { "Desarrollar y potenciar los procesos de oralidad } \\
\text { y escucha en los niños de preescolar, a partir de } \\
\text { la literatura infantil en los entornos familiares y } \\
\text { escolares" (López, 2018, p. 12) }\end{array}$ \\
\hline $\begin{array}{l}\text { Godoy, } \\
\text { Eloidit }\end{array}$ & Perú & 16 & $\begin{array}{l}3-5 \\
\text { años }\end{array}$ & $\begin{array}{l}\text { Mejorar significativamente la comprensión de } \\
\text { textos a través de la lectura de imágenes para } \\
\text { incentivar a la lectura a niños de nivel inicial. }\end{array}$ \\
\hline $\begin{array}{l}\text { Guevara, } \\
\text { Yolanda; } \\
\text { Rugerio, } \\
\text { Juan }\end{array}$ & México & 80 & $\begin{array}{l}3-5 \\
\text { años }\end{array}$ & $\begin{array}{l}\text { "Analizar la relación que guardan las acciones } \\
\text { didácticas de las profesoras de preescolar con } \\
\text { los tipos de interacción y las conductas que sus } \\
\text { alumnos muestran durante las actividades de } \\
\text { lectura de cuentos" (Guevara, Yolanda; Rugerio, } \\
\text { Juan, 2017, p. 730) }\end{array}$ \\
\hline $\begin{array}{l}\text { gMora, } \\
\text { Jenny; } \\
\text { Morales, } \\
\text { Sandra }\end{array}$ & Colombia & 9 & $\begin{array}{l}5-6 \\
\text { años }\end{array}$ & $\begin{array}{l}\text { Ofrecer una alternativa de trabajo significativo } \\
\text { para promover la lectura en un ambiente de } \\
\text { aprendizaje presencial, fortalecido a través de } \\
\text { espacios virtuales, mejor conocido como b- } \\
\text { learning. }\end{array}$ \\
\hline $\begin{array}{l}\text { Acevedo, } \\
\text { Pilar; } \\
\text { Duarte, } \\
\text { Edy; } \\
\text { Higuera, } \\
\text { Marlen }\end{array}$ & Colombia & 30 & $\begin{array}{l}\text { 6-7 } \\
\text { años }\end{array}$ & $\begin{array}{l}\text { "Determinar cuáles son las incidencias en el nivel } \\
\text { de lectura crítica, como resultado de la } \\
\text { implementación de las estrategias de lectura en } \\
\text { sus tres momentos: antes, durante y después } \\
\text { para el desarrollo de comprensión literal, } \\
\text { inferencial y crítico" (Acevedo, Duarte, y Higuera, } \\
2016, \text { p. 52). }\end{array}$ \\
\hline $\begin{array}{l}\text { Briseño, } \\
\text { Lilia; Niño, } \\
\text { Magaly; } \\
\text { Florez, Rita }\end{array}$ & Colombia & 48 & $\begin{array}{l}5-7 \\
\text { años }\end{array}$ & $\begin{array}{l}\text { "Favorecer el desarrollo de los procesos de } \\
\text { lectura y escritura de los niños del nivel } \\
\text { preescolar a través de estrategias didácticas } \\
\text { basadas en el uso del cuento infantil para su } \\
\text { óptimo desempeño" (Briseño, Niño, \& Florez, } \\
2019, \text { p. 12) }\end{array}$ \\
\hline $\begin{array}{l}\text { Navarro, } \\
\text { Marianela; } \\
\text { Orellana, } \\
\text { Pelusa; } \\
\text { Baldwin, } \\
\text { Paula }\end{array}$ & Chile & 698 & $\begin{array}{l}3-7 \\
\text { años }\end{array}$ & $\begin{array}{l}\text { Mostrar que la Escala de Motivación Lectora es } \\
\text { un "instrumento confiable y válido en su versión } \\
\text { en español, aportando así, una herramienta para } \\
\text { su uso con fines de investigación o aplicable en } \\
\text { el aula, permitiendo a investigadores y docentes } \\
\text { profundizar en la motivación lectora en niños de } \\
\text { habla hispana" (Navarro Marianela; Orellana } \\
\text { Pelusa; Baldwin Paula, 2018, p. 2) }\end{array}$ \\
\hline
\end{tabular}

Mora, Juan;

Galán,

Arturo; España 206

López,

6-7 Confirmar la relevancia de la Influencia Familiar

Martha

años IF en el aprendizaje de la lectura desde el punto de vista de la acción educativa en el hogar.

Pascual,

María;

Madrid,

Dolores;

España 677

$5-6$

"Identificar los factores predominantes en el

Estrada;

años

Ligia

Ortega, S;

Vega, L; México 26

Poncelis, M

6
3-4 lectura dialógica de cuentos en niños de primer años año de preescolar, siguiendo las estrategias planteadas por Whitehurst $(1994,1988) "$ (Ortega, Vega, \& Poncelis, 2016, p. 390) 
Santiago,

Dina:

Gutiérrez,

Yomina;

Martínez;

Tulis

Medina,

Magda;

Leal, Ana

Colombia 55

Camino,

María

Gabriela

Ecuador 12

No

Betancur,

M; Florez,

A.

Colombia proporciona

información
3-5

años

"Evidenciar el impacto de la aplicación de los cuentos infantiles como estrategia didáctica para el desarrollo progresivo del lenguaje oral y expresivo de los niños y niñas". (Santiago, Gutierrez, Martínez y Tulis, 2016, p. 15)

"Evaluar el efecto de un programa basado en los principios de lectura y la escritura como proceso 5-7 sobre la producción de textos, la comprensión de años lectura y las habilidades metacognitivas de un grupo de niños de tercero y cuarto grado". (Medina, Magda; Leal, Ana, 2019, p. 32)

"Determinar la incidencia de los bits de lectura a través de la identificación de las ventajas y desventajas de estos para mejorar la estimulación lectora en los niños comprendidos de 2 a 4 años de edad" (Camino, 2015, p. 11).

"Insertar a la biblioteca como integrante de un sistema pedagógico social complementario a 6-7 través de planes y programas encaminados a años incentivar la adquisición de conocimientos y el hábito de la lectura libre" (Betancur y Florez, 2016, p. 88)

"Demostrar cómo la lectura de cuentos puede convertirse en una oportunidad para enseñar

Llamazares,

María; $\quad$ España 24

María

Fuente: Mercado, 2018; Cortés y García, 2017; Lluch y Sánchez, 2017; Rojas y Cruzata, 2016; López, 2018; Godoy, 2016; Guevara y Rugerio, 2017; Mora y Morales, 2016; Acevedo et al., 2016; Briseño et al., 2019; Navarro et al., 2018; Mora et al., 2016; Pascual et al., 2018; Ortega et al., 2016; Santiago et al., 2016; Medina y Leal, 2019; Camino, 2015; Betancur y Florez, 2016; Llamazares y Alonso, 2016.

En la tabla 1, se exponen los datos que determinan la selección de la unidad de análisis, los mismos que contemplan autores de diferentes países; así como, el rango de edad, que cumple el sentido de temporalidad deseado (de 3 a 7 años).

\section{Tabla 2:}

Prácticas motivadoras hacia la lectura en edades tempranas

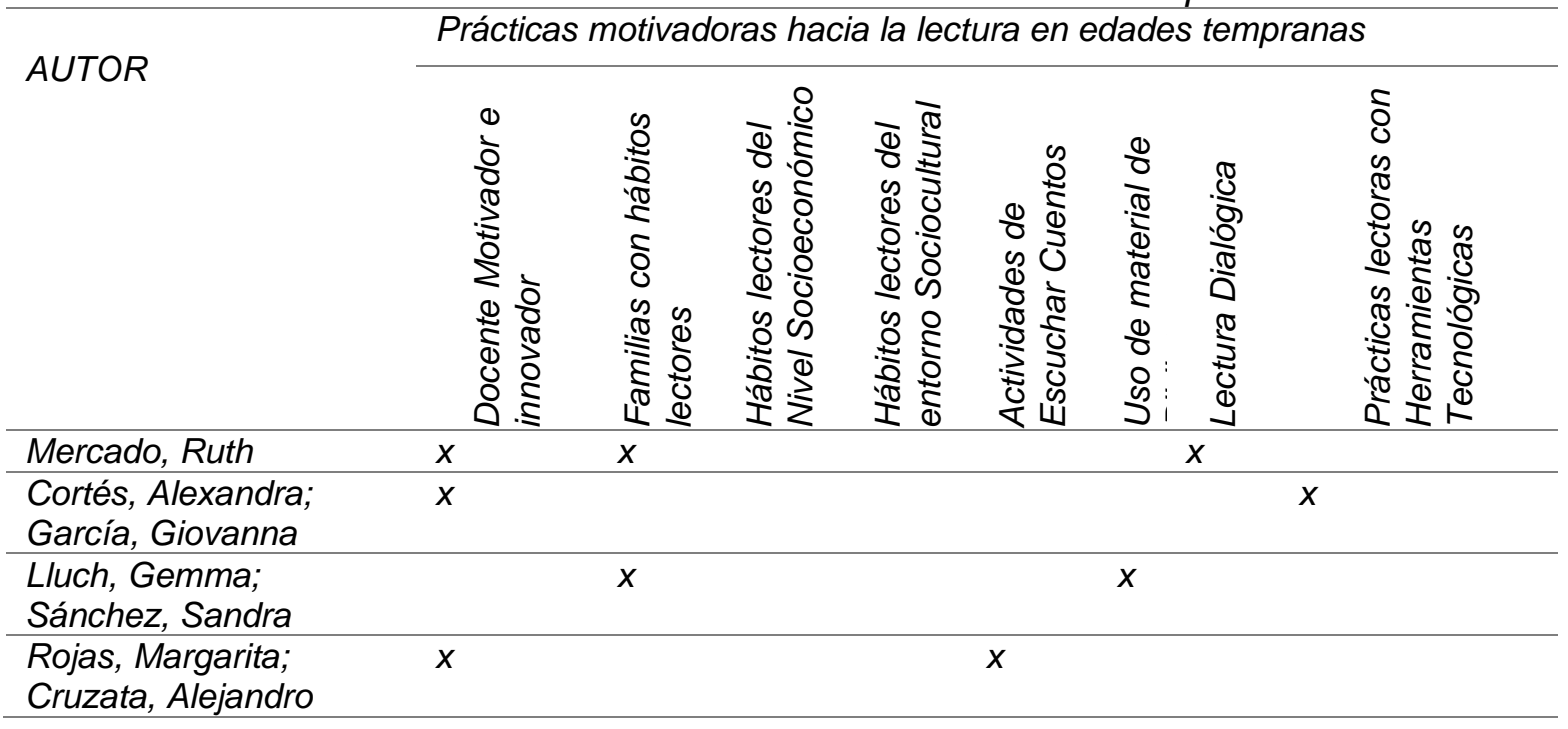




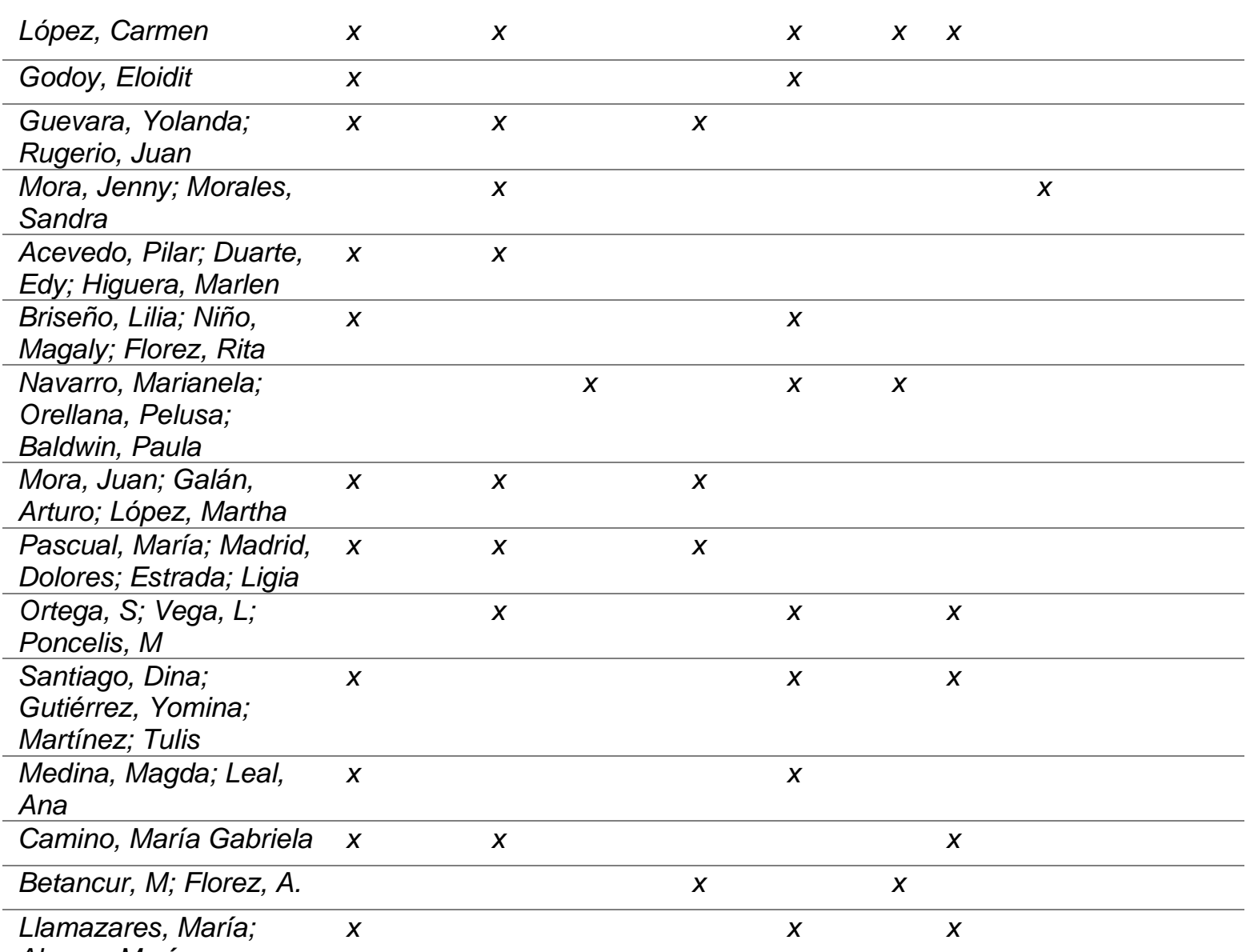

Alonso, María

Fuente: Mercado, 2018; Cortés y García, 2017; Lluch y Sánchez, 2017; Rojas y Cruzata, 2016; López, 2018; Godoy, 2016; Guevara y Rugerio, 2017; Mora y Morales, 2016; Acevedo et al., 2016; Briseño et al., 2019; Navarro et al., 2018; Mora et al., 2016; Pascual et al., 2018; Ortega et al., 2016; Santiago et al., 2016; Medina y Leal, 2019; Camino, 2015; Betancur y Florez, 2016; Llamazares y Alonso, 2016.

En la tabla 2, se observa que las prácticas motivadoras hacia la lectura en edad temprana más frecuentes analizadas por los autores son las relacionadas con los docentes, como motivadores del hábito lector en sus estudiantes, a través de la experiencia innovadora, lo que requiere de actualización frecuente.

Desde el aspecto familiar donde existen padres con hábitos de lectura, motivan a sus hijos a imitar este comportamiento, generando un ambiente de enseñanza con el ejemplo, creando una mayor posibilidad de que los niños de ese hogar generen el gusto lector. Otra de las prácticas más sustantivas es el escuchar cuentos, mediante esta actividad los estudiantes desarrollan el sentido descifrador a través de la curiosidad, imaginación, interpretación, y deducción para el desarrollo de explicaciones que van en función de lo que escucharon, aportando la motivación de la práctica lectora.

Por otro lado, la lectura dialógica promueve la interrelación entre el maestro y los niños, en este tipo de actividad se practica la pre-lectura, ya que, al realizar el intercambio de roles, el niño va adoptando el papel de narrador de manera paulatina. El uso del material bibliográfico como táctica motivadora, permite que los infantes se relacionen con los textos, haciéndolos parte de su entorno, a la vez que tienen la oportunidad de revisarlos, lo que consiente relacionarlos en el contexto lector.

Las prácticas de hábitos lectores derivados del entorno socioeconómico y cultural, así como el desarrollo del hábito lector a partir de herramientas tecnológicas son 
actividades que no influyen en la motivación de la lectura, por lo que su uso es poco frecuente.

\section{DISCUSIÓN}

Nuestra investigación encontró datos importantes en algunos investigadores sobre la motivación de la lectura en edades tempranas y que están expuestos en la tabla 1, en la que expresan: preocupación por identificar distintos métodos de enseñanza para la lectura y perfección de los procesos de producción oral; búsqueda de estrategias que los profesores puedan implementar en el aula mediante didácticas tecnológicas con fundamentos pedagógicos para mejorar la comprensión de los textos, utilizando el trabajo significativo y promoviendo la lectura crítica, persuasiva, emocional y apropiada a la edad.

Se evidencia que los docentes buscan prácticas innovadoras mediante sistemas de ilustración auto sostenidos, que impulsan la curiosidad y el deseo de contenido intelectual, fomentando la creatividad, la expansión del conocimiento y la promoción de la calidad académica del estudiante. Para Navarro et al. (2018) existe una relación entre la lectura, la frecuencia y el hábito lector, indicando que mientras más motivados están los lectores, con mayor facilidad desarrollarán la costumbre de leer.

De acuerdo con los resultados de la tabla 2, para que los infantes inicien la práctica lectora en edades tempranas, uno de los elementos importantes debe ser la imagen, ya que ella produce información que el niño luego puede relacionar con la escritura. Existe una incidencia casi unánime, identificando al docente como el principal motivador de la lectura. Según Llamazares y Alonso (2016) se le atribuye tal responsabilidad porque es el encargado de llevar a cabo el proceso de enseñanza aprendizaje, utilizando técnicas innovadoras que buscan soluciones a la falta de hábitos lectores, que desencadenan un déficit dentro del sistema de educación.

Otro aspecto para generar hábitos lectores es el hogar, según Lluch y Sánchez (2017), despierta la motivación lectora mediante la imitación; los hijos copian conductas de los padres; se observa, que se produce un proceso de simulación del comportamiento de los adultos que termina por convertirse en costumbre. También el escuchar cuentos, el material bibliográfico y la lectura dialógica, promueven el hábito lector, según López (2018), estos tipos de estrategias, potencia la oralidad y la literatura infantil en el entorno familiar y escolar, enseñándole al niño a comunicarse a través del lenguaje y apoyándose en la lectura de quien está hablando.

En consecuencia, la motivación lectora tiene una relación estrecha con el desarrollo del hábito lector, siendo preciso que los docentes identifiquen aquellas prácticas más eficientes para estimular la costumbre de leer en los niños a edad temprana. También se identifica una limitación en el estudio relacionada con la falta de referentes bibliográficos para Ecuador en el periodo 2020. En tal sentido: El docente (motivador de la lectura), apoya a que el niño asuma el proceso lector como una actividad que permite el alcance de nuevos conocimientos, promoviendo el disfrute de escenarios poco conocidos, generando una óptica en la que el infante use la lectura para disfrutar los contenidos; más no, para ser evaluado por lo leído.

La familia tiene un rol fundamental como promotora de la práctica lectora a edad temprana, porque es la encargada de estimular el desarrollo de las habilidades y competencias de la primera infancia, las mismas que determinarán las bases de la formación de su personalidad y de la relación social, y mientras más estimulada sea la actividad lectora; el hábito lector se desarrollará con mayor facilidad. 
La estimulación del hábito lector a través de leer cuentos permite crear en los niños no solo una asociación con los textos, sino que los involucra como lectores y escritores activos, aunque no lo realicen de la forma adecuada y convencional, de esta manera se estimula la creatividad, la memoria, el desarrollo del lenguaje, el escuchar con atención, pero sobre todo promueve la recreación del infante.

El uso de material de biblioteca para fomentar la lectura genera una relación entre el niño y los textos, permitiéndoles identificarse con el proceso del desarrollo del hábito lector, a la vez, que se siente como parte activa, dado que tienen acceso a los diferentes tipos de documentos que les despiertan interés y que buscarán conocer con mayor profundidad.

La lectura dialógica como promotora del hábito lector, permite crear ambientes en el que el desarrollo de la motivación lectora es igualitario para todos los miembros del salón, utilizando la diversidad de las interacciones como elementos que permiten mejorar el proceso de aprendizaje, en donde el lector le otorga un significado a lo que lee, pero lo enriquece al compartirlo con otros lectores.

\section{REFERENCIAS BIBLIOGRÁFICAS}

Acevedo, P., Duarte, E., Higuera, M. (2016). Innovación en las estrategias de lectura y su incidencia en la competencia lectora. Educación y Ciencia, 19, 53-69.

Bernal, L. (2017). La literatura y la competencia lectora: Degustando la lectura. Bogotá. Obtenido de https://bit.ly/3vHXVeY

Cortés, Alexandra; García, Giovanna. (2017). Estrategias pedagógicas que favorecen el aprendizaje de niñas y niños de 0 a 6 años de edad en Villavicencio- Colombia. Revista Interamericana de Investigación, Educación y Pedagogía, 10(1), 125-143.

Domingo, J. (2017). ¿Qué leen los que no leen? México: Océano Travesía. https://bit.ly/3gKvMzK

Fonseca, L., Migliardo, G., Simian, M., Olmos, R. (2019). Estrategias para Mejorar la Comprensión Lectora: Impacto de un Programa de Intervención en español. Psicología Educativa, 25(2), 91-99. https://doi.org/10.5093/psed2019a1

Godoy, E. (2016). Aplicación De La Estrategia “Lectura De Imágenes”, En La Comprensión De Textos En Los Niños y Niñas del Nivel Inicial En La I.E.I N 377 De Cochamarca, Distrito De Obas Yarowilca 2015. Huánco: Universidad Católica Los Ángeles Chimbote. Obtenido de https://bit.ly/3y5G1Er

Guevara, Yolanda; Rugerio, Juan. (2017). Interacciones Profesor-Alumnos Durante Lectura De Cuentos En Escuelas Preescolares Mexicanas. Investigacion, 22(74), 729-749.

Llamazares, M., Alonso, M. (2016). Lectura Compartida Y Estrategias De Comprensión Lectora En Educación Infantil. Revista Iberoamericana de Educación, 71, 1-228. https://bit.ly/3x1JV14

Lluch, G., Sánchez, S. (2017). La promoción de la lectura: un análisis crítico de los artículos de investigación. Facultad de Ciencias de la Educación y Humanidades, 40(4), 1-14. doi: http://dx.doi.org/10.3989/redc.2017.4.1450

López, C. (2018). Desarrollo de la oralidad y la escucha en los niños de preescolar del primer ciclo a partir de la literatura infantil. Bogotá: Universidad Distrital Francisco José de Caldas. https://bit.ly/3h4OH8p

Medina, Magda; Leal, Ana. (2019). Efectos de un programa basado en los postulados de la lectura y escritura como proceso sobre la calidad de comprensión y producción de textos expositivos en niños de tercero y cuarto de primaria. 31-62: Institución Educativa Distrital Bernardo Jaramillo, Sede B, Jornada Tarde. https://bit.ly/3qBypqT

Mora, Jenny; Morales, Sandra. (2016). Fortalecimiento en los Procesos Lecto-Escritos en Primera Infancia a través de Blended-Learning. Revista Iberoamericana sobre Calidad, Eficacia y Cambio en Educación, 14(1), 117-135.

Navarro, M., Orellana, Baldwin, P. (2018). Validación de la Escala de Motivación Lectora en Estudiantes Chilenos de Enseñanza Básica. Universidad de los Andes, 27(1), 1-17.

Rojas, M., Cruzata, A. (2016). La comprensión lectora en estudiantes de educación primaria en. Revista de Educación. 9(7), 337-356.

Serna, M., Rodríguez, A., Etxaniz, X. (2017). Biblioteca escolar y hábitos lectores en los escolares de Educación Primaria. Ocnos: Revista de Estudios sobre Lectura. 16(1), 18-49. Obtenido de http://dx.doi.org/10.18239/ocnos_2017.16.1.1205. 